\title{
HOMEM-MÁQUINA: AS PRODUÇÕES DISCURSIVAS E OS PROCESSOS DE SUBJETIVIDADE DESENVOLVIDOS NA INTERAÇÃO DO SUJEITO COM REDES DIGITAIS
}

\author{
Fausi dos SANTOS ${ }^{1}$ \\ Maria Regina MOMESSO ${ }^{2}$ \\ Paulo Rennes Marçal RIBEIRO ${ }^{3}$
}

RESUMO: O artigo apresenta, a partir da Análise do Discurso de linha francesa, a concepção de sujeito e sua vinculação com o corpo, a razão e os efeitos de sentido produzidos nas redes digitais. Parte da noção de sujeito pensante na filosofia cartesiana, no qual a razão exerce poder sobre o corpo e a matéria. O corpo para Descartes é um obstáculo a ser superado pela mente. Já em Foucault, há um deslocamento da noção de sujeito enquanto unidade ontológica para a noção de sujeito como uma função do discurso. Para Foucault, o sujeito se faz como produto de uma interação sócio-biológica, que se faz e refaz segundo a função e o posicionamento que ocupa no ato discursivo. As redes digitais são espaços de subjetividade, onde ocorre o deslocamento do sujeito em relação ao seu corpo que é anulado momentaneamente enquanto veículo ou invólucro da função-sujeito, dando vazão para a livre circulação do sujeito e da mente em espaços rizomáticos e digitais.

PALAVRAS-CHAVE: Redes. Sujeito. Mente. Corpo.

\section{Os limites do corpo na rede: uma primeira aproximação filosófica}

René Descartes (1596-1650) em suas Meditações Metafísicas (DESCARTES, 2011) faz pela dúvida metódica, clara distinção em relação à força do pensamento sobre a matéria, afirma serem os órgãos dos sentidos (visão, audição, paladar, olfato, tato), bem como as paixões, a fonte do erro e da visão distorcida da realidade. Somente a mente, ou, "razão ativa" seria capaz de garantir o conhecimento verdadeiro. Tal potência ativa é o que daria ao homem a capacidade de ir além. Existem, portanto, duas

\footnotetext{
${ }^{1}$ Mestre em Linguística. Unifran - Universidade de Franca. Pesquisador Capes/Obeduc/Inep em Análise do Discurso. Professor. UNIESP - Instituto Educacional do Estado de São Paulo. Bauru - SP - Brasil. 17013-190-fausifilo@hotmail.com.

2 Doutora em Linguística e Análise do Discurso. UNESP - Universidade do Estado de São Paulo, Campus de Assis. Professora. CTI//UNESP - Colégio Técnico Industrial de Bauru e do Programa de PósGraduação em Educação Sexual da UNESP - Universidade Estadual Paulista. Araraquara - SP - Brasil. 14801-385 - maryqueenmomesso@gmail.com.

${ }^{3}$ Livre-Docente em Sexologia e Educação Sexual. UNESP - Universidade Estadual Paulista. Professor Adjunto no Departamento de Psicologia da Educação e Coordenador do Programa de Pós-Graduação em Educação Sexual. UNESP - Universidade Estadual Paulista. Araraquara - SP - Brasil. 14801-385 paulorennes@fclar.unesp.br.
} 
realidades para Descartes (2011), a res extensa, passiva e sem significado em si mesmo e a res cogitans, ou razão pensante, ativa e com capacidade de nomear o mundo e a si mesma. Daí a máxima cartesiana, Penso, logo existo!

De fato, o corpo para Descartes (2011) é um obstáculo a ser superado pela mente. A debilidade do corpo e os limites físicos impõem zonas de exclusão à mente e a impede de externar todo seu potencial criativo. As interdições advindas das proporções físicas, da idade e interação com o meio faz do corpo uma prisão a ser superada pela coisa pensante.

A concepção de sujeito e sua vinculação com o corpo e a razão terá em Michel Foucault outro tipo de vinculação e função. Em sua obra As Palavras e as Coisas (FOUCAULT, 1999), Foucault enuncia “[...] a morte do homem e o nascimento do sujeito”. Rompe a partir desse conceito com a concepção de sujeito enquanto indivíduo, o sujeito da razão em Descartes (2011) com atributos ontológicos (inatos e inerentes à própria razão), para concebê-lo como produzido por funções que lhes são exteriores. Atesta, dessa forma, o descentramento do sujeito e sua condição pelos discursos.

Afirma Fernandes (2012) sobre essa noção de sujeito enquanto função dos discursos,

[...] o sujeito passa a ser considerado como uma função, ou como uma posição a ser ocupada nos discursos. A morte do homem, enquanto individualidade no mundo, e o nascimento do sujeito pelos saberes que o circundam possibilitam a Foucault, em momento posterior à arqueologia, refletir sobre a relação constitutiva entre sujeito e poder, o que o leva, inclusive, a escavar as formas sociopolíticas voltadas para o biopoder. (FERNANDES, 2012, p.59).

Há um deslocamento da noção de sujeito enquanto unidade ontológica para a noção de sujeito como uma função do discurso. Sujeito como produto de uma interação sócio-biológica, que se faz e refaz segundo a função e o posicionamento que ocupa no ato discursivo. Em suas aulas proferidas e reunidas em Poder Psiquiátrico (FOUCAULT, 2006), o autor explica que “[...] a vinculação da função-sujeito a um corpo determinado é coisa que só se pode fazer de maneira descontínua, incidente, momentânea, por exemplo, em cerimônias”. (FOUCAULT, 2006, p.130).

Segundo Fernandes (2012, p.59), na questão da relação entre sujeito e corpo, para Foucault a função sujeito não se reduz a um indivíduo corpóreo, mas "[...] é necessário um corpo que funcione como suporte para o sujeito, para o exercício da função-sujeito". O corpo se converte num invólucro onde o sujeito transita e se desloca 
em sua função de emissor do discurso. Corpo enquanto espaço e matéria necessária para o funcionamento da função sujeito.

A fim de exemplificar esse conceito sujeito-corpo, Fernandes (2012) utiliza um exemplo oferecido por Foucault na figura do corpo do Rei. O Rei é uma posição-sujeito, com um corpo, mas quando ocorre o falecimento desse corpo, o Rei continuará existindo, pois como uma função, terá outro corpo como suporte, para sua existência,

[...] o Rei, para assegurar sua soberania, deve ser um sujeito com corpo [...] este corpo do rei, que mantém juntas todas essas relações de soberania, não pode desaparecer como o indivíduo X ou Y que acaba de morrer. É necessária, portanto, certa permanência do corpo do rei; é necessário que o corpo do rei não seja simplesmente sua singularidade somática, tem de ser, além disso, a solidez de seu reino, da sua coroa. [...] a relação de soberania põe em ligação, aplica algo como um poder político no corpo, mas nunca faz a individualidade aparecer. (FOUCAULT, 2006, p.57).

Portanto, para Fernandes (2012), nesse sentido não é o corpo que está em questão, mas o sujeito de ação, produzido por uma exterioridade social, cultural e política. Isso se aplica a todo sujeito uma vez que exterioridade atua sempre, por meio de discursos, na produção de subjetividade, e o sujeito é um efeito de subjetividade.

A relação do sujeito com o corpo enquanto objeto sobre o qual recaí o poder é trabalho por Foucault (2004) na obra Vigiar e Punir quando o autor afirma que os castigos impostos sobre o corpo visam atingir o sujeito e não uma singularidade somática:

[...] o corpo está também diretamente mergulhado num campo político; as relações de poder tem alcance imediato sobre ele; elas o investem, o marcam, o dirigem, o suplicam, sujeitam-no a trabalhos, obrigam-no a cerimônias, exigem-lhe sinais. Este investimento político do corpo está ligado, segundo relações complexas e recíprocas, à sua utilização econômica [...] o corpo é investido por relações de poder e dominação. (FOUCAULT, 2004, p.25).

Segundo Fernandes (2012), se o corpo é tomado como força produtiva e submisso, ele encontra-se investido de um sujeito de ação, que está posto em relação a outros sujeitos, definidos e distintos entre si pelas suas posições.

Tanto a noção de sujeito como cogito em Descartes (2011), com uma função inata e ativa, quanto a noção de sujeito enquanto função discursiva que ocupa distintas posições em sua ação em Foucault, reservam ao corpo um espaço de submissão. Corpo 
investido de um sujeito que atua, que se age em função de uma razão (Descartes) ou por funções de discurso (Foucault). Corpo como o limite da subjetividade, um suporte formado e moldado segundo os parâmetros de um sujeito.

A constatação de Descartes e Foucault (respeitando as diferenças conceituais de cada um, lembrando que para Descartes o sujeito cognitivo é uma realidade dada de forma inata, enquanto para Foucault é construída pelo discurso e por isso, é um sujeito de transição) dos limites impostos pelo corpo à mente parecem ser diluídas e minimizadas com o advento da sociedade informacional e com as tecnologias digitais. Existem entusiastas das chamadas novas tecnologias que veem o corpo como um vestígio indigno fadado a desaparecer em breve.

Longe de compartilhar uma postura tão radical, de anulação do corpo nas redes digitais, parece prudente pensar que a disseminação e uso de tais maquinarias computacionais quebra, em parte, as fronteiras do corpo em relação à mente. A presença diária das redes sociais nas variadas atividades de trabalho ou lazer, a criação de novos softwares de compartilhamento de informação. A utilização de equipamentos eletrônicos que codificam as ondas cerebrais transformando-as em movimento de próteses robóticas, ou ainda a utilização dessas maquinarias nas relações amorosas, faz delas importante instrumento na ampliação e potencialização das ações mentais.

Mas o que é o sujeito, pela ótica foucaultiana, nas redes digitais? É um sujeito produzido pelo discurso informacional com função de transitoriedade deslocada do corpo e que circula cumprindo múltiplas posições em uma rede permeada por interconexões virtuais. O sujeito digital circula em um campo de enunciação, dotado de variados gestos de interpretação que o posiciona de forma variada, ora o colocando em determinada zona de produção, ora o conduzindo a outras regiões discursivas. Por isso, não existe um sujeito nas maquinarias computacionais, mas um conjunto de sujeitos que ocupam zonas de interpretação cumprem determinados conjunto de funções e produz uma série de efeitos de sentido. O sujeito na rede sempre se encontra em espaços de interconexão, abrindo e fechando portas de informação, acessando e desligando funções discursivas, segundo sua necessidade e emergência.

A rede é um espaço de subjetividade, onde ocorre o deslocamento do sujeito em relação ao seu corpo que é anulado momentaneamente enquanto veículo ou invólucro da função-sujeito, dando vazão para a livre circulação do sujeito em espaços rizomáticos e digitais. A rede digital é uma tecnologia de poder sobre o corpo, é um instrumento com ação discursiva forte o suficiente para deslocar e inserir o sujeito em enunciações 
paradgmáticas (relativo a modelos) que se movem por redes de informação de origem diversa e que por serem externas ao sujeito produzem efeitos de sentido e patrocinam a elaboração de determinadas subjetividades, ou sujeitos, com funções determinadas para campos de enunciação específicos.

Nesse sentido, o sujeito pai, esposo, chefe de família que cumpre a função do "homem casado", quando adentra a rede social, se transforma no soldado espartano no jogo em rede Age of Mythology, ao se deslocar desse universo se converte no blogueiro que discute moral e política em uma comunidade virtual, por conta disso possui centenas de seguidores no twitter que simpatizam de suas ideias. Ora ou outra, esse sujeito acessa sua conta no facebook, posta fotos de suas férias na África do Sul e elabora comentários sobre os lugares e pessoas, suas postagens são curtidas e replicadas por amigos e familiares. Quantas funções cumprem esse sujeito nessas relações discursivas nas redes sociais? O de guerreiro espartano, blogueiro político, criador de opinião com grupo de seguidores, aventureiro etc. Com certeza enquanto sujeito ocupa variadas posições, pois transita em variados discursos e se molda enquanto sujeito em cada um deles. Tudo isso quanto sujeito de cognição fora de seu corpo, lançado a cenários desenvolvidos digitalmente que quebram a linha do tempo e do espaço, o faz assumir diferentes posicionamentos e efeitos de sentido.

É um sujeito submetido à dinamicidade do meio digital, um "eu" nômade que circula em espaços construídos a partir de uma cópia do mundo, esboço do real, com total controle do programador. A liberdade do sujeito na rede se dá no trânsito das linguagens lógicas de como as informações são dispostas.

Orlandi (2009) na obra Análise do Discurso: princípios e procedimentos, discute sobre o assujeitamento do sujeito.

A forma-sujeito histórica que corresponde à da sociedade atual
representa bem a contradição: é um sujeito ao mesmo tempo livre e
submisso. Ele é capaz de uma liberdade sem limites e uma submissão
sem falhas: pode tudo dizer, contanto que se submeta à língua para
sabê-la. Essa é a base do que chamamos assujeitamento. (ORLANDI,
2009, p.50).

Desse modo, a língua e seu conjunto de regras é a única fronteira existente entre o sujeito real e o sujeito virtual. Para comunicar e fazer transitar a informação na rede se faz necessária a língua. Talvez seja essa a única dimensão que limita totalmente a ação do sujeito discursivo nas redes sociais. 


\section{Será o fim do corpo?}

O último século foi fértil em momentos históricos que alteraram significativamente as tecnologias. A Primeira e Segunda Guerra Mundial, a corrida armamentista e espacial em plena tensão da Guerra Fria nas décadas de cinquenta e sessenta, desenvolveram mecanismos para veiculação rápida de informação e otimização de cálculos para o direcionamento de bombas. O fato é que a aplicação prática dessas tecnologias transcendeu o universo militar e gradativamente chegou à vida cotidiana do cidadão comum.

A evolução das tecnologias digitais transformou a percepção do corpo nas três dimensões do espaço (altura, largura e profundidade), pois infiltrou o corpo em um espaço rizomático, com zonas de intersecção que se movem e transformam em devires e multiplicidade de deslocamento. Espaço de passagem e caminhos que se sobrepõem por uma avalanche de informações. O espaço ocupado pelo corpo na rede é um espaço de transição, de circulação nômade.

Illouz (2011) ao discutir o significado do corpo na internet afirma que no momento em que o sujeito adentra o ciberespaço há certa anulação do corpo.

[...] a internet é apresentada como uma tecnologia descorporificadora, e que desmaterializa o corpo de maneira positiva [...] essa ideia, por sua vez, é compatível com um "discurso central utópico em torno da tecnologia da computação", centrado no "potencial oferecido pelos computadores para que os seres humanos escapem do corpo [...] $\mathrm{Na}$ cultura do computador, a corporalização é comumente representada como uma barreira lamentável à interação com os prazeres computacionais. Na escrita cibernética, é comum fazer-se referência ao corpo como 'a carne', a carne morta que cerca a mente ativa que constitui o eu autêntico. (ILLOUZ, 2011, p.108).

A ideia de descorporificação nas redes digitais permite que os sentimentos evoluam e fluam com certa liberdade para a elaboração de um "eu" incorpóreo, fruto da mente e dos discursos que o cercam. Um eu de consciência que ganha forma fora do corpo e pode circular sem as barreiras físicas.

Outros autores compartilham dessa leitura, como é o caso de Le Breton (2003, p.123) ao afirmar que “[...] o corpo não é mais uma fronteira identitária, mas vestígio deixado no espaço". O corpo é convertido em uma memória ou traço, passando a ocupar um espaço secundário na relação com o sujeito, 
[...] conectados ao ciberespaço, os corpos se dissolvem. "Suspenso no universo do computador", diz Heim, "o cibernauta abandona a prisão do corpo a prisão do corpo e entra num mundo de sensações digitais." O viajante da infoesfera não se sente mais preso a um corpo físico, ele conduz sucessivas explorações sobre identidades geralmente diferentes, em um mundo imaterial. (BRETON, 2003, p.124).

Segundo Breton (2003), não importa sua idade, seu sexo, nem mesmo se está doente ou é deficiente, ele é livre para se mover à vontade e segundo sua competência em um universo de dados. Seu corpo físico se comparado aos múltiplos corpos virtuais que são produzidos se torna um vestígio limitado, um traço antropológico sem importância na rede.

Em 2006, os irmãos cineastas americanos Wachiwski apresentaram o cenário de um mundo artificial, como produto de uma inteligência artificial. Tendo como nome Matrix, esse sistema maquínico se alimenta da ilusão de liberdade e autonomia dos indivíduos. Os personagens que se libertam da Matrix se deslocam de uma cidade a outra, transitam em espaços pasteurizados construídos digitalmente, adquirem habilidades e poderes que superam os limites do corpo, podendo inclusive aprender habilidades de lutas e manuseio de armas com apenas a instalação de um programa digital na memória.

Nesse sentido, o corpo era uma extensão do mundo digital, pois seu deslocamento era enunciado por meio da vontade do sujeito cognitivo, que uma vez conectado à máquina se desligava do corpo podendo dessa forma se deslocar livre em múltiplos espaços. Espaços descontínuos que eram acessados e fechados em um único instante, de um hotel a um bar, de um terraço a uma praça onde o telefone servia de canal para religar o sujeito ao seu corpo.

Frente aos pressupostos de Matrix, surge o questionamento, se tal relação já não existe no mundo não ficcional do cinema, no mundo virtual onde os sujeitos transitam em realidades pasteurizadas dotadas de regras, valores e texturas próprias. Desenvolvidas com perfeição a fim de oferecer aos usuários simulações de sensações e experiências tão fortes e prazerosas que chegam a superar as experiências do corpo na vida real.

Sem sair de casa, conectado à rede, é possível lançar-se nos rios da Amazônia e desfrutar a riqueza de suas águas com seus peixes e botos cor de rosa, se infiltrar na floresta e conhecer animais exóticos e pássaros coloridos e por meio de aplicativos 
ouvir seus cantos fantásticos. Despir a mulher ideal num jogo erótico de um site de relacionamento; dialogar durante horas com ciberamigos espalhados por várias regiões do mundo, tudo simultaneamente, sem as regras do tempo e espaço. Não se conhece nada desses amigos além do pseudônimo e as reações textuais que expressam, ao participar de um jogo de RPG.

Continua Le Breton (2003) nesse sentido,

[...] é possível viver em uma cidade virtual, com apartamento, profissão, lazer, vizinhos, amigos, ir a uma sala de espetáculos, informa-se sobre o caminho com outros internautas que vão para lá etc. É possível assistir a partos transmitidos ao vivo, e a própria não escapa mais à Net. Um site canadense permite acompanhar um funeral por meio de uma câmera conectada à rede. [...] tendo dispensado o corpo, toas as metamorfoses são permitidas. (BRETON, 2003, p.128).

O ciberespaço construiu um modo de existência, com linguagens, códigos, símbolos, culturas e discursos próprios, um conjunto de valores particulares para dar movimento e dinamicidade aos sistemas de produção virtual. É por meio desse modo de existência que as relações se descorporificam e emergem na construção de sujeitos com funções específicas no ciberespaço, existências fluidas e prolongadas somente enquanto acessadas pelo usuário.

O ciberespaço, para Breton (2003), é um instrumento da multiplicação de si, uma prótese da existência. Nesse sentido, favorece toda potência do pensamento e promove a libertação da mente dos limites corporais.

As superfícies criadas pelo ciberespaço circulam em "planos de imanência"4 com potência suficiente para produzir zonas de enunciação. A natureza das zonas de enunciação depende do espaço que ocupa na rede, ou seja, é produzida em campos onde determinada função ou necessidade surgem como "Acontecimento." ${ }^{5}$ Nesse sentido, o mundo virtual é um campo de enunciação onde circulam imanências que criam variados efeitos de sentido, de forma a responder as necessidades variadas do internauta, que se desloca do corpo e mergulha nas linhas de fuga dos planos de imanência, circula sobre variados sentidos.

\footnotetext{
${ }^{4}$ Relativo à filosofia deleuziana, o conceito plano de imanência está ligando à ideia de intensidade, ou zonas poder com matéria sem significado ou sentido, é um campo de pura potência "para". Campo de imanência é um simples fato da própria existência como uma possibilidade ou potencialidade.

${ }^{5} \mathrm{O}$ acontecimento sustenta-se em dois níveis no pensamento de Deleuze: condição sob a qual o pensamento pensa (encontro com um fora que força a pensar, corte do caos por um plano de imanência), objetidades especiais do pensamento (o plano é povoado apenas por acontecimentos ou devires, cada conceito é a construção de um acontecimento sobre o plano).
} 
É nesse sentido que o corpo na rede se torna nulo, dando vazão ao sujeito que se coloca em variadas posições e aciona diferentes mecanismos de produção de sentido.

Como afirma Breton (2003),

[...] o tempo da conexão abre-se a um mundo descorporificado, sem interioridade, pura superfície. $O$ corpo não se impõe nem mesmo como injunção de identidade, pois a esse respeito todos os jogos são possíveis. Pessoas deficientes ou gravemente doentes têm a oportunidade de mover-se à vontade, sem temer obstáculos físicos, ou comunicar-se sem temer serem estigmatizadas. O peso do corpo é eliminado, não importa a idade, a saúde, a conformação física; os internautas encontram-se em um plano de igualdade justamente pelo fato de o corpo ser colocado entre parênteses. (BRETON, 2003, p.131).

Portanto, o corpo na máquina é reduzido à função de ser apenas o suporte para a livre expressão do sujeito discursivo, corpo entre parênteses como afirma Breton (2003). Não há como duvidar que há certa liberdade de circulação do sujeito enquanto mente pensante e desejante no ciberespaço, que cruza as fronteiras do tempo e do espaço e digitalmente deixa sua marca nos diferentes espaços que circula e ocupa no ato da navegação. A condição de existência desse sujeito na rede é de transitoriedade e fluidez, uma vez que assume diferentes funções e aciona variados efeitos de sentido.

\section{Nativos digitais: uma breve reflexão sobre a interação da geração $Z$ com 0 ciberespaço}

Não há consenso entre os estudiosos sobre a nomenclatura "geração Z" relacionada aos nascidos na década de 1990 e por assim dizer classificados como "nativos digitais." A polêmica está ligada a ideia de que existem pessoas nascidas nessa década que ainda não tiveram acesso às redes digitais e outras que só foram apresentadas a pouco tempo a essas tecnologias. Existe, portanto, um problema de ordem sociocultural, que para estudiosos como Mônica Fantin ${ }^{6}$ interfere na divisão clara entre as características da geração Z.

Kämpf (2011), em seu artigo, “A geração Z e o papel das tecnologias digitais na construção do pensamento", cita as palavras de Fantin e Rivoltella (2010) em relação à sua resistência em relação ao termo "nativo digital”,

\footnotetext{
${ }^{6}$ Mônica Fantin, é coordenadora do Núcleo Infância, Comunicação, Cultura e Arte, da Universidade
} Federal de Santa Catarina (UFSC). 
[...] em primeiro lugar, diversos pesquisadores discutem o uso desse termo e argumentam que não é possível isolar a tecnologia e sua capacidade de produzir efeitos sobre as pessoas' de outros elementos do contexto sociocultural que também interferem nessa relação. $\mathrm{O}$ neurocientista Edoardo Boncinelli afirma que o cérebro do homem é o mesmo há 120.000 anos e que a cultura digital é muito recente para afirmarmos que ela realmente esteja produzindo tais mudanças. Já para a neurocientista cognitivista Maryanne Wolf, há um processo de mudança de paradigma em curso que pode estar reorganizando o cérebro das novas gerações a partir de novos parâmetros, o que a leva a perguntar sobre perdas e ganhos que o amanhã reserva às crianças e aos jovens, mas que hoje ainda não é possível saber. (KAMPF, 2011, p.2).

Nesse sentido, qualquer gesto de interpretação sobre a geração $\mathrm{Z}$ deve levar em conta tais polêmicas evitando assim posições extremadas e otimistas demais. Mesmo porque o tempo de uso de tais maquinarias é relativamente curto para classificar e demonstrar mudanças significativas nos padrões de organização cognitiva das novas gerações.

Posição mais equilibrada é conduzida pelo pesquisador italiano Pier Cesare Rivoltella, estudioso da relação entre mídia e educação, que concorda com a nomenclatura geração $\mathrm{Z}$, enquanto marco que regulamenta as pessoas nascidas na década de noventa onde o uso da internet e das tecnologias digitais de informação já se faziam presente. No entanto, argumenta que as barreiras que separam adultos e crianças no uso dessas maquinarias se estreitam cada vez mais por estar presente no dia a dia, sendo utilizadas em vários segmentos da vida social, seja em casa, no ambiente de trabalho, no lazer e no entretenimento. Portanto, não faz sentido segmentar o uso das tecnologias digitais a uma determinada geração.

Rivoltella, Kampf e Fantin (2011) mostram que o uso das tecnologias tem aproximado e não distanciado adultos e crianças. Ele cita o exemplo “[...] do uso do celular e das redes sociais configurando-se como espaço de negociação, cumplicidade e compartilhamento de interesses que envolvem e acabam por aproximar diferentes gerações”. (RIVOLTELLA; KAMPF; FANTIN, 2011, p.2).

O fato é que as plataformas digitais fazem parte do cotidiano da maioria das pessoas, ignorar sua presença faz com que se torne praticamente impossível viver na sociedade contemporânea, pois para a execução da mais simples tarefa como a compra de um produto no mercado, ou o pedido de uma mercadoria tudo passa por uma intricada trama de comandos digitais. A rapidez e agilidade que tais redes digitais proporcionam tem mudado muito a relação do indivíduo com a realidade à sua volta, 
pois a quantidade e circulação de informação são cada vez mais rápida o que acelera a percepção que o sujeito possui sobre si mesmo e o mundo. Basta pensar, na década de 60 ou 70, o tempo necessário para que uma informação percorresse um longo espaço até chegar ao seu destinatário, e a revolução que internet causou no encurtamento dos espaços por meio da aceleração da informação.

Por isso, uma das características segundo Fantin, que identifica as novas gerações é a multimidialidade, ou a capacidade de utilizar vários meios, seja ele textual, gráfico, sonoro e visual para executar diferentes tarefas simultaneamente, o que desenvolve diversas habilidades transmidiáticas (capacidade de migrar de um meio para outro com muita rapidez) de forma interativa com uma grande quantidade de informação acessadas e transmitidas ao mesmo tempo,

[...] as crianças multitarefa, que estão habituadas a controlar diversas mídias ao mesmo tempo (navegar na internet, enviar e receber mensagens pelo celular, ouvir músicas no tocador de $\mathrm{mp} 3$ ), desenvolvem um estilo de atenção muito diferente de quem cresceu em ambiente alfabético e está acostumado a focar sua atenção no texto escrito e habituado a raciocinar em termos de um objeto preciso e específico, tendo uma atenção mais focalizada. (FANTIN; RIVOLTELLA, 2010, p.3)

Segundo Fantin e Rivoltella (2010) a atenção das crianças multitarefas é pulverizada em diversos elementos perceptivos, o que resulta numa distribuição periférica de muita informação e certa dificuldade em focar a atenção em um único objeto por muito tempo. Esse ritmo e estilo de atenção pulverizada são mal compreendidos e interpretados, sendo associados, por exemplo, a hiperatividade, termo bastante comum atualmente, sendo utilizado, como afirma Fantin, de forma muito generalizado para classificar o comportamento de crianças e adolescentes.

O que se constata, portanto, é um tipo ou modo de comportamento específico que o uso da multimidialidade provoca em quem faz seu uso sistemático. Esse modo de comportamento pode ser mais acentuado na "geração Z" uma vez que cresce manuseando e incorporando naturalmente essas diferentes funções digitais. Por isso mesmo, consegue circular e desenvolver habilidade transmidiáticas com muita facilidade em diferentes plataformas computacionais. ${ }^{7}$

${ }^{7}$ O pesquisador José Armando Valente, coordenador associado do Núcleo de Informática Aplicada à Educação (Nied) da Unicamp afirma, porém, que é questionável a ideia de que a facilidade no acesso à informação esteja produzindo crianças com maior capacidade de construir conhecimento. Valente lembra que alguns autores também classificam a geração Z de "geração panqueca" ou "crepe": espalhada e fina; 
Orlandi (2009) afirma que a linguagem é o lugar da constituição dos sujeitos, ora, o ciberespaço é hoje um lugar nômade, no qual, diferentes linguagens (imagem, texto, áudio, interatividade) circulam e constituem sujeitos determinados, com tipos específicos de produção discursiva que movem múltiplos efeitos de sentido. As relações de poder que a linguagem digital exerce sobre a realidade dos usuários torna possível a transformação no modo como interpretam e se relacionam com o mundo à sua volta, incorporando ao seu discurso pessoal toda a influência que o ciberespaço tem sobre ele como formador de efeitos de sentido.

As condições de produção que as redes digitais proporcionam aos seus usuários, como por exemplo, a multimidialidade, resulta em efeitos de sentidos específicos, com uma condição existencial inserida no contexto histórico que o sujeito se encontra, isso determina o tipo de linguagem e comportamento que o sujeito assume perante a realidade à sua volta, tal característica explica a condição multitarefa que a geração $\mathrm{Z}$ manifesta.

Segundo Orlandi (1996) a historicidade inserida na linguagem determina enquanto condições de produção os efeitos de sentido que um sujeito irá produzir,

[...] isso implica o reconhecimento de que há uma historicidade inscrita na linguagem que não nos permite pensar na existência de um sentido literal, já posto, e nem mesmo que o sentido possa ser qualquer um, já que toda interpretação é regida por condições de produção. Essa disciplina propõe um deslocamento das noções de linguagem e sujeito que se dá a partir de um trabalho com a ideologia. Assim, passa-se a entender a linguagem enquanto produção social, considerando-se a exterioridade como constitutiva. O sujeito, por sua vez, deixa de ser centro e origem do seu discurso para ser entendido como uma construção polifônica, lugar de significação historicamente constituído. (ORLANDI, 1996, p.49).

Segundo Orlandi (1996) o sujeito é determinado pelos elementos externos a ele que dão origem e sentido ao seu discurso. A presença constante e ostensiva das redes digitais no cotidiano das pessoas torna se condição de produção capaz de criar um determinado tipo de existência com discurso específico. Sendo as redes digitais plataformas externas ao sujeito e constituídas de construções polifônicas, transformam o discurso desse sujeito (geração Z) em uma produção que para circular necessita de variadas plataformas midiáticas (texto, imagem, som, gráfico).

cujos membros estão em todos os lugares, porém não conseguem manter a atenção nem se aprofundar em nada. 


\section{MAN-MACHINE: THE DISCURSIVE PRODUCTIONS AND THE DEVELOPED SUBJECTIVITY PROCESS IN THE INTERACTION OF THE SUBJECT WITH DIGITAL NETWORKS}

ABSTRACT: The article presents from the analysis of the French Discourse the conception of the subject and its link with the body, reason and meaning effects produced in digital networks. Part of the notion of thinking subject in Cartesian philosophy, in which reason exerts power over the body and matter. The body for Descartes is an obstacle to be overcome by the mind. For Foucault, there is a change from the notion of subject as ontological unity to the notion of the subject as a speech function. For him the subject is made as the product of a socio-biological interaction which makes and remakes according to the function and the position it occupies in the speech act. Digital networks are subjectivity spaces where there is a displacement of the subject in relation to its body that is set aside momentarily as vehicle or wrapper function-subject, giving vent to the free movement of the subject and mind in rhizomatic and digital spaces.

KEYWORDS: Network. Subject. Mind. Body.

\section{REFERENCIAS}

DESCARTES, R. Meditacoes metafísicas. São Paulo: WMF Martins Fontes, 2011.

FANTIN, M.; RIVOLTELLA, P. C. Crianças na era digital: desafios da comunicação e da educação. Revista Estudos Universitários, Sorocaba, v.36, n.1, p.89-104, jun. 2010.

FERNANDES, C. A. Discurso e sujeito em Michel Foucault. São Paulo: Intermeios, 2012.

FOUCAULT, M. As palavras e as coisas. Tradução de Salma Tannus Muchail. 8.ed. São Paulo: Martins Fontes, 1999.

Poder psiquiátrico. São Paulo: Martins Fontes, 2006.

Vigiar e Punir. Petrópolis: Vozes, 2004.

ILLOUZ, E. O amor nos tempos do capitalismo. Rio de Janeiro: Zahar, 2011.

KÄMPF, C. A geração Z e o papel das tecnologias digitais na construção do pensamento. ComCiência, Campinas, n.131. Disponível em: 〈http://comciencia.scielo.br/pdf/cci/n131/a04n131.pdf〉. Acesso em: 21 ago. 2014.

LE BRETON, D. Adeus ao corpo. In: NOVAES, A. O homem máquina: a ciência manipula o corpo. São Paulo: Companhia das Letras, 2003. p.123-137.

ORLANDI, E. P. Análise de discurso: princípios e procedimentos. Campinas: Pontes, 2009. 
Discurso e leitura. 3.ed. São Paulo: Cortez; Campinas: Editora da Universidade Estadual de Campinas, 1996.

RIVOLTELLA, P. C.; KAMPF, C.; FANTIN, M. A geração Z e o papel das tecnologias digitais na construção do pensamento. ComCiência, Campinas, n.131, 2011. Disponível em: <http://comciencia.scielo.br/scielo.php?script=sci_arttext\&pid=S1519-

$76542011000700004 \& \operatorname{lng}=\mathrm{en} \& \mathrm{nrm}=\mathrm{iso}>$. Acesso em: 23 out. 2013. 